\title{
Power fuzzy adaptive control for wind turbine
}

\author{
Yacine Hocini ${ }^{1}$, Ahmed. Allali ${ }^{2}$, Houari Merabet Boulouiha ${ }^{3}$ \\ ${ }^{1,2,3}$ Faculty of Electrical Engineering, University of Sciences and Technology of Oran, Algeria \\ ${ }^{3}$ Departement of Electrical Engineering, Ecole Polytechnique Oran, Algeria
}

\begin{tabular}{l}
\hline \hline Article Info \\
\hline Article history: \\
Received Sep 29, 2019 \\
Revised Mar 9, 2020 \\
Accepted Apr 25, 2020 \\
\hline
\end{tabular}

\section{Keywords:}

Active and reactive powers

DFIG

Direct vector control

Fuzzy logic

Wind energy

\section{Corresponding Author:}

Yacine Hocin,

Faculty of Electrical Engineering,

University of Sciences and Technology of Oran,

El Mnaouar, BP 1505, Bir El Djir 31000, Algeria.

Email: yacine.hocini@gmail.com

\begin{abstract}
In recent years, wind energy has become one of the most promising renewable energy sources. The doubly-fed induction generator (DFIG) is currently the most common type of generator used in wind farms. This paper describes an approach for the independent control of the active and reactive power of the variable-speed DFIG. This paper deals with the control of the active and reactive powers in a DFIG designed for a wind system. The simulation model including a $7 \mathrm{KW}$ - DFIG driven by a wind turbine, a PWM inverter and the proposed control strategy are developed and implemented using Matlab Simulink.
\end{abstract}

Copyright $\odot 2020$ Institute of Advanced Engineering and Science. All rights reserved.

\begin{tabular}{|c|c|c|c|}
\hline \multicolumn{4}{|c|}{ Nomenclatures } \\
\hline$L_{m}$ & Mutual inductance & $K d$ & Derivate gain of controller \\
\hline$g$ & Slide & $e$ & error \\
\hline $\mathrm{s}$ & Laplace operator & $K_{p}$ & Proportional gain of controller \\
\hline$S$ & Surface & $\mathrm{J}$ & Inertia of the generator \\
\hline$\Omega_{s}$ & Stator electrical speed & $\Omega_{m e c}$ & generator shaft speed \\
\hline$\Omega_{m}$ & Rotor mechanical speed & $C_{p}$ & power coefficient \\
\hline$T_{e m}$ & Electromagnetic torque & $T_{a e r}$ & aerodynamic torque \\
\hline$P_{S}$ & Stator active power & $\mathrm{B}$ & blade pitch angle \\
\hline$Q_{s}$ & Stator reactive power & $\mathrm{R}$ & blade radius \\
\hline $\mathrm{Tg}$ & torque produced from the multiplier & $\Omega_{\text {turbine }}$ & angular speed of the turbine \\
\hline$f$ & viscous friction coefficient & $V$ & wind speed \\
\hline $\mathrm{Ki}$ & Integral gain of controller & $\lambda$ & tip speed ratio \\
\hline$\sigma$ & coefficient of dispersion & $\rho$ & the air density \\
\hline
\end{tabular}

\section{INTRODUCTION}

Electrical energy is a key and vital element for the social and economic development of our modern society. During the last century, due to the massive industrialization and substantial growth in the world population, electric energy consumption has seen a significant increase which has led to a progressive decline in fossil fuels reserves. Electricity generation from alternative and renewable energy resources has now been accepted as a viable solution to address these energy problems. 
Wind power is among the world's fastest growing renewable energy technology $[1,2]$. Due to its geographical location, Algeria is considered as one of the most promising countries in Africa with regard to renewable energies such as solar and wind. Algeria has a moderate wind conditions with wind speeds ranging from 2 to $6 \mathrm{~m} / \mathrm{s}$ and increasing gradually as we go toward the south-west Figure 1. The maximum wind resources can be found in the region of Adrar with an average wind speed of $6 \mathrm{~m} / \mathrm{s}$. The region of Oran [2], is ranked among the windiest areas of Algeria with an average wind speed is $4.5 \mathrm{~m} / \mathrm{s}$.

The abundance of this clean and free energy has attracted much interest in recent years and extensive research is being undertaken to improve the efficiency of the electromechanical conversion and quality of the energy supplied. The aim of this work is to present the performance comparison of wind energy conversion system based on a doubly fed induction generator by using the conventional fuzzy-PI controller and adaptive fuzzy controller, a direct vector control strategy made the object of analysis for the independent control of active and reactive power.

The two regulators are tested and compared using two different specifications, i.e. the tracking of the references, and robustness by varying the parameters of the system. Adaptive fuzzy controller Control strategy was adopted to control both the active and reactive power; the simulation results show that this strategy has fast dynamic response and good robustness with regard to parametric variations. This paper is organized as follows: Section 2 describes the overall model of the wind energy conversion system. Section 3 of the paper presents the design of the fuzzy logic control (FLC). In this section, the description of fuzzy controller with adaptive gain control (FAGC) is presented. Finally, the simulation results and conclusions are summarised in Section 4 and 5 respectively.

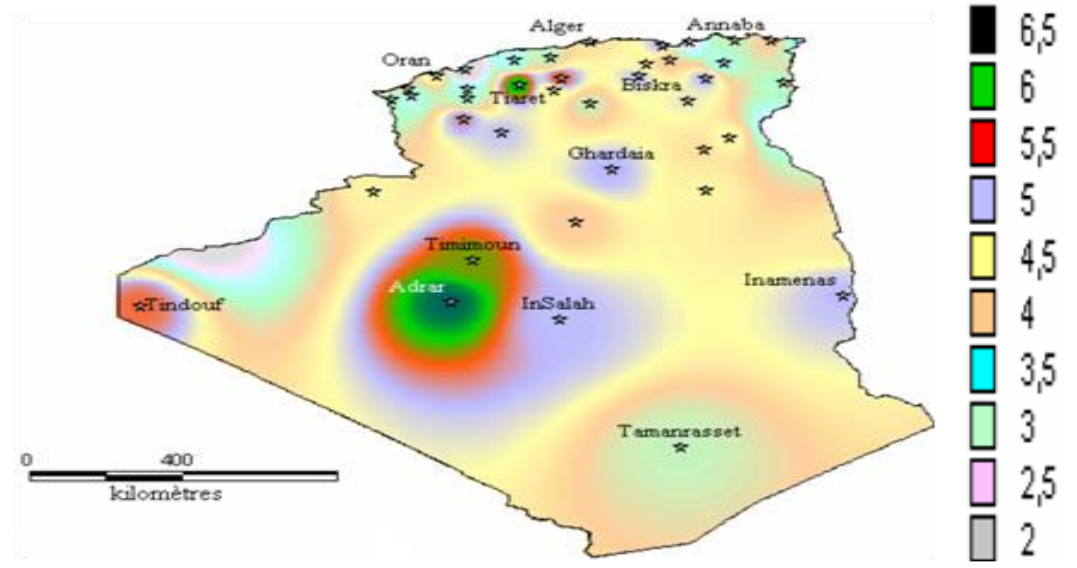

Figure 1. Atlas of average wind speed of Algeria estimated at $10 \mathrm{~m}$ above the ground [3]

\section{MODELLING OF WIND TURBINE GENERATOR SYSTEM}

The overall diagram of a wind energy conversion system connected to the power line is shown in Figure 2 [4]. Table and Figure are presented center, as shown below and cited in the manuscript. The blades convert the kinetic energy of the wind into mechanical energy that results in a force and a torque which causes the rotation of the DFIG by means of a shaft. This rotation provides mechanical power to the DFIG. The rotor is connected to a power converter which controls the amplitude and frequency of the voltage.

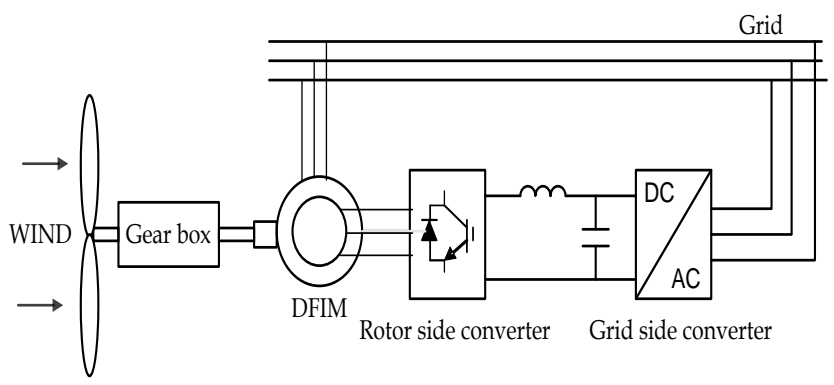

Figure 2. Wind energy conversion system 


\subsection{Model of the turbine}

The block diagram of the dynamic model of the turbine described in Figure 3 [5-7].

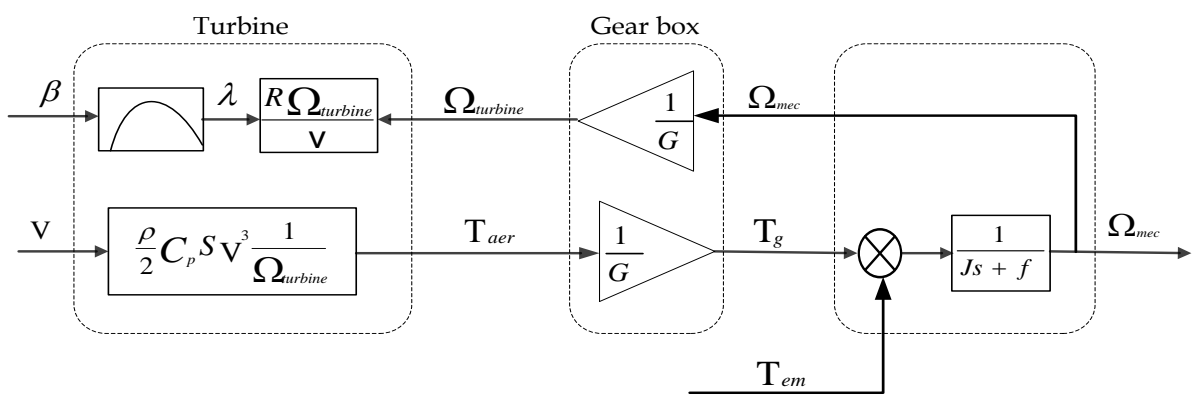

Figure 3. Dynamic model of the turbine

The aerodynamic power appearing at the rotor of the turbine is $[8,9]$ :

$$
P_{\text {aer }}=C_{P} \cdot P_{v}=C_{P}(\lambda, \beta) \cdot \frac{\rho S V^{3}}{2}
$$

The aerodynamic torque is directly determined by;

$$
\mathrm{T}_{\text {aer }}=\frac{P_{\text {aer }}}{\Omega_{\text {turbine }}}=C_{p} \cdot \frac{\rho s v^{3}}{2} \cdot \frac{1}{\Omega_{\text {turbine }}}
$$

\subsection{Model of the DFIG}

The mathematical model of the asynchronous machine in matrix form is written as [10-12]: The state space equations of the induction machine can be written in matrix;

$$
\frac{d[x]}{d t}=[A][X]+[B][U]
$$

where;

$$
\begin{aligned}
& x=\left[\begin{array}{llll}
\phi_{d s} & \phi_{q s} & \mathrm{i}_{d r} & \mathrm{i}_{d s}
\end{array}\right]^{T} U=\left[\begin{array}{llll}
V_{d s} & V_{q s} & V_{d r} & V_{q r}
\end{array}\right]^{T} \\
& \mathbf{A}=\left[\begin{array}{cccc}
-\frac{1}{\mathrm{~T}_{\mathrm{s}}} & \omega_{\mathrm{s}} & \frac{\mathrm{L}_{\mathrm{m}}}{\mathrm{T}_{\mathrm{s}}} & 0 \\
-\omega_{\mathrm{s}} & -\frac{1}{\mathrm{~T}_{\mathrm{s}}} & 0 & \frac{\mathrm{L}_{\mathrm{m}}}{\mathrm{T}_{\mathrm{s}}} \\
\frac{1-\sigma}{\mathrm{L}_{\mathrm{m}} \sigma \mathrm{T}_{\mathrm{s}}} & \frac{1-\sigma}{\mathrm{L}_{\mathrm{m}} \sigma} \omega_{\mathrm{m}} & -\left(\frac{1}{\sigma \mathrm{T}_{\mathrm{r}}}+\frac{1-\sigma}{\sigma \mathrm{T}_{\mathrm{s}}}\right) & \omega_{\mathrm{r}} \\
\frac{1-\sigma}{\mathrm{L}_{\mathrm{m}} \sigma} \omega_{\mathrm{m}} & \frac{1-\sigma}{\mathrm{L}_{\mathrm{m}} \sigma \mathrm{T}_{\mathrm{s}}} & -\omega_{\mathrm{r}} & -\left(\frac{1}{\sigma \mathrm{T}_{\mathrm{r}}}+\frac{1-\sigma}{\sigma \mathrm{T}_{\mathrm{s}}}\right)
\end{array}\right] \\
& B=\left[\begin{array}{cccc}
1 & 0 & 0 & 0 \\
0 & 1 & 0 & 0 \\
-\frac{1-\sigma}{\sigma \mathrm{L}_{\mathrm{m}}} & 0 & \frac{1}{\sigma L_{r}} & 0 \\
0 & -\frac{1-\sigma}{\sigma \mathrm{L}_{\mathrm{m}}} & 0 & \frac{1}{\sigma L_{r}}
\end{array}\right]
\end{aligned}
$$

where: $\mathrm{T}_{\mathrm{s}}=\frac{\mathrm{L}_{\mathrm{s}}}{\mathrm{R}_{\mathrm{s}}}, \mathrm{T}_{\mathrm{r}}=\frac{\mathrm{L}_{\mathrm{r}}}{\mathrm{R}_{\mathrm{r}}}$ and $\sigma=1-\frac{\mathrm{L}_{\mathrm{m}}{ }^{2}}{\mathrm{~L}_{\mathrm{s}} \mathrm{L}_{\mathrm{r}}}$ 
The active and reactive powers are given by the following expressions [10, 13]:

$$
\left\{\begin{array}{l}
P=V_{d s} I_{d s}+V_{q s} I_{q s} \\
Q=V_{q s} I_{d s}-V_{d s} I_{q s}
\end{array}\right.
$$

Taking into account the orientation of the flux: [14-18];

$$
\begin{aligned}
& \phi_{\mathrm{ds}}=\phi_{\mathrm{s}} ; \phi_{\mathrm{qs}}=0 \\
& \phi_{\mathrm{qs}}=0 \\
& \left\{\begin{array}{l}
P=V_{d s} I_{d s}+V_{q s} I_{q s} \\
Q=V_{q s} I_{d s}-V_{d s} I_{q s}
\end{array}\right. \\
& \left\{\begin{array}{l}
I_{d s}=\frac{\phi_{s}}{L_{s}}-\frac{\mathrm{L}_{\mathrm{m}}}{L_{s}} I_{d r} \\
I_{q s}=-\frac{\mathrm{L}_{\mathrm{m}}}{L_{s}} I_{q r}
\end{array}\right. \\
& \left\{\begin{array}{c}
\phi_{d r}=\left(L_{r}-\frac{\mathrm{L}_{\mathrm{m}}^{2}}{L_{s}}\right) I_{d r}+\frac{V_{s} \mathrm{~L}_{\mathrm{m}}}{\omega_{s} L_{s}} \\
\phi_{q r}=\left(L_{r}-\frac{\mathrm{L}_{\mathrm{m}}^{2}}{L_{s}}\right) I_{q r}
\end{array}\right. \\
& \left\{\begin{array}{c}
\mathrm{V}_{d r}=R_{r} I_{d r}+\left(L_{r}-\frac{\mathrm{L}_{\mathrm{m}}^{2}}{L_{s}}\right) \frac{d I_{d r}}{d t}-g \omega_{s}\left(L_{r}-\frac{\mathrm{L}_{\mathrm{m}}{ }^{2}}{L_{s}}\right) I_{q r} \\
V_{q r}=R_{r} I_{q r}+\left(L_{r}-\frac{\mathrm{L}_{\mathrm{m}}^{2}}{L_{s}}\right) \frac{d I_{q r}}{d t}+g \omega_{s}\left(L_{r}-\frac{\mathrm{L}_{\mathrm{m}}{ }^{2}}{L_{s}}\right) I_{d r}+g \omega_{s} \frac{V_{s} \mathrm{~L}_{\mathrm{m}}}{\omega_{s} L_{s}}
\end{array}\right.
\end{aligned}
$$

In these equations, $\mathrm{Rs}, \mathrm{Rr}, \mathrm{Ls}$ and $\mathrm{Lr}$ denote respectively the resistances and inductances of the stator windings and rotor, $\mathrm{M}$ is the cyclic mutual inductance, $\omega \mathrm{r}=\mathrm{p} . \Omega \mathrm{r}$ is the rotor speed (with $\mathrm{p}$ the number of pole pairs) and $\omega s$ is the synchronous angular speed. $v d s, v q s, v d r, v q r, i d s, i q s, i d r, i q r, \phi d s$, $\phi q s, \phi d r$ and $\phi q r$ are respectively the direct and quadratic components of voltages, currents and fluxes in the stator and rotor. While these equations are used to establish a block diagram of the electrical system to be controlled as shown in Figure 4 [10]. Knowing these equations, it is then possible to synthesize the regulators, where the input blocks relating Vdr to Vqr represent the simplified rotor converter model.

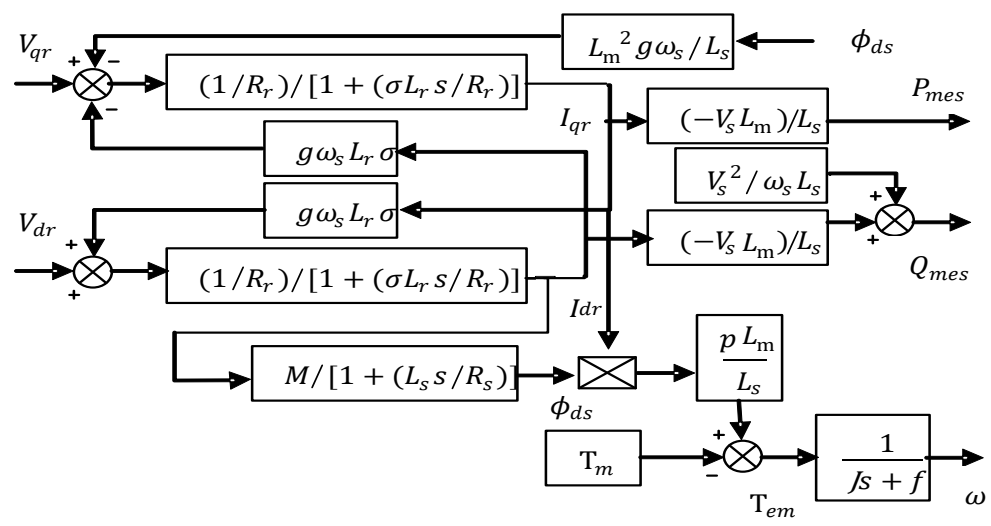

Figure 4. Block diagram of the system to be controlled 


\section{DESIGN OF THE PROPOSED FUZZY LOGIC-BASED CONTROLLERS}

\subsection{FLC controller $[14,15,16,19,20]$}

The following structure show the diagram of an FLC controller, where Figure 5 represents Fuzzy-PI control strategy whereas Figure 6 show the membership functions applied.

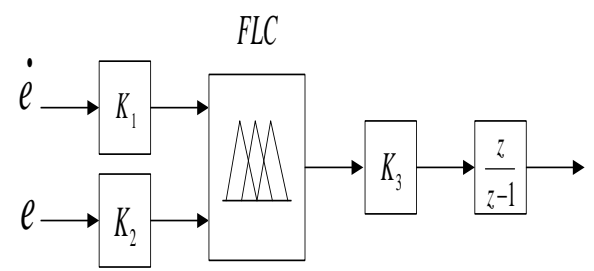

Figure 5. Structure of the FLC controller

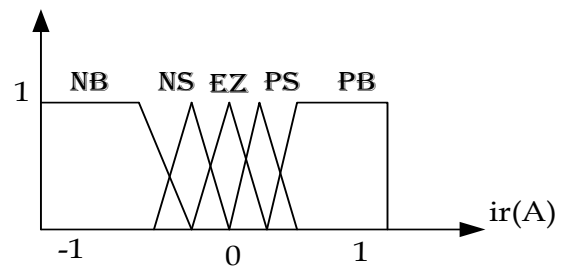

Figure 6. Membership functions (triangular membership function with have a trapezoidal ends)

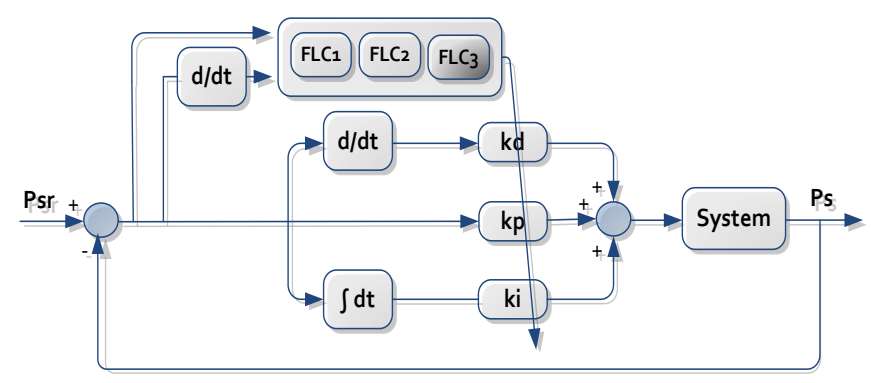

Figure 7. Structure of the fuzzy adaptive gain controller [21-25]

The proposed adaptation of gains is expressed as follows shown in Figures 7:

$$
k_{p}{ }^{\prime}=k_{p}+f(e+\Delta e), k_{i}{ }^{\prime}=k_{i}+f(e+\Delta e) \text { and } k_{d}{ }^{\prime}=k_{d}+f(e+\Delta e)
$$

where $k_{p}{ }^{\prime}, k_{i}{ }^{\prime}$ and $k_{d}{ }^{\prime}$ are the adaptation gains and $f$ is the output of adaptation action based on Tables 1-3, $e$ and $\Delta e$ are the error e and its variation. Center of gravity approach is used to defuzzify the output variable of the system.

The selected membership functions symmetrical trapezoidal shape. We considered the method of center of gravity defuzzification. Subsets fuzzy membership are noted as follows:

NB: Negative Big; PZ: Positive Zero; NZ: Negative Zero; NM: Negative Medium PS: Positive Small; PB: Positive Big; NS: Negative Small: PM: Positive Medium Z: Zero

The adaptive fuzzy controller proposed based mainly an adaptive mechanism by fuzzy logic (MAF). The main aim of fuzzy adaptation mechanism is to build a table of inference rules for online adaptation of gains. The novelty of the method is the online adjusting parameters of the corrector in order to keep the desired performance level is mainly to define a fuzzy controller that adjusts the correction parameters and generates her new parameters so that adapts to all conditions of operations, being based on error and its derivative.

Table 1. Inference table established for the adaptation gain $\mathrm{kp}$

\begin{tabular}{cccccccc}
\hline $\mathrm{e}_{\mathrm{n}} \Delta \mathrm{e}_{\mathrm{n}}$ & $\mathrm{NB}$ & $\mathrm{NM}$ & $\mathrm{NS}$ & $\mathrm{Z}$ & $\mathrm{PS}$ & $\mathrm{PM}$ & $\mathrm{PB}$ \\
\hline NB & PB & PM & PB & PB & PB & Z & NB \\
NM & PM & PS & PM & PM & PM & NS & NM \\
NS & PS & Z & PS & PS & PS & NM & NB \\
PS & NB & NB & PS & PS & PS & Z & PS \\
PM & NB & NS & PM & PM & PM & PS & PM \\
PB & NB & Z & PB & PB & PB & PM & PB \\
\hline
\end{tabular}


Table 2. Inference table established for the adaptation gain ki

\begin{tabular}{ccccccccc}
\hline $\mathrm{e}_{\mathrm{n}} \Delta \mathrm{e}_{\mathrm{n}}$ & $\mathrm{NB}$ & $\mathrm{NM}$ & $\mathrm{NS}$ & $\mathrm{NZ}$ & $\mathrm{PZ}$ & $\mathrm{PS}$ & $\mathrm{PM}$ & $\mathrm{PB}$ \\
\hline $\mathrm{NB}$ & PB & PM & PM & PS & NB & NM & Z & Z \\
NM & PB & PM & PS & PS & NM & NS & Z & PS \\
NS & PB & PS & Z & Z & Z & Z & PS & PB \\
Z & PB & PS & Z & Z & Z & Z & PM & PB \\
PS & PM & PS & Z & Z & Z & Z & PM & PB \\
PM & PS & Z & NS & NM & PS & PS & PB & PB \\
PB & Z & Z & NM & NB & PM & PM & PB & PB \\
\hline
\end{tabular}

Table 3. Inference table established for the adaptation gain $\mathrm{kd}$

\begin{tabular}{|c|c|c|c|c|c|c|c|}
\hline $\mathrm{e}_{\mathrm{n}} \Delta \mathrm{e}_{\mathrm{n}}$ & NB & NM & NS & $\mathrm{Z}$ & PS & PM & PB \\
\hline NB & PB & PB & PB & $\mathrm{NM}$ & $\mathrm{NM}$ & $\bar{Z}$ & $\mathrm{Z}$ \\
\hline $\mathrm{NM}$ & PB & PB & PM & NS & NS & Z & PS \\
\hline NS & PB & PB & PS & Z & Z & PS & PB \\
\hline Z & PB & PM & PS & Z & PS & PM & PB \\
\hline PS & PM & PS & Z & Z & PS & PM & PB \\
\hline PM & PS & $\mathrm{Z}$ & NS & NS & PM & PB & PB \\
\hline PB & Z & Z & NM & NM & PB & PB & PB \\
\hline
\end{tabular}

\section{SIMULATION RESULTS}

This section presents the simulation results to evaluate and compare the performance of the proposed controllers.

\subsection{Fuzzy control}

Tests were carried out which consist in achieve active and reactive power levels while machine is driven fixed speed. Test conditions:

Active power remains almost constant at $-7000 \mathrm{~W}$.

- At t $=2$ sec: reactive power level $Q_{\text {ref }}$ ranges from 10,000 to $-10,000 \mathrm{VAR}$.

- At $\mathrm{t}=1.5 \mathrm{sec}$ : active power echelon, $P_{\text {ref }}$ range from -3000 to $-6000 \mathrm{~W}$ then -6000 to $-8000 \mathrm{~W}$.

- The reactive power of the machine is maintained almost constant at $10000 \mathrm{~W}$.

Figures 8 and 9 show simulation results of the different step inputs for an active and a reactive power. The results show that levels of references of active and reactive power imposed on the DFIG are followed without overshoot and a response time $0.225 \mathrm{sec}$ for active power and $0.35 \mathrm{sec}$ for reactive power. Figure 9 show the pursuit references of powers is satisfied. Moreover, decoupling is assigned on the set change. This is reflected by a pic of active power and a relative drop of reactive power

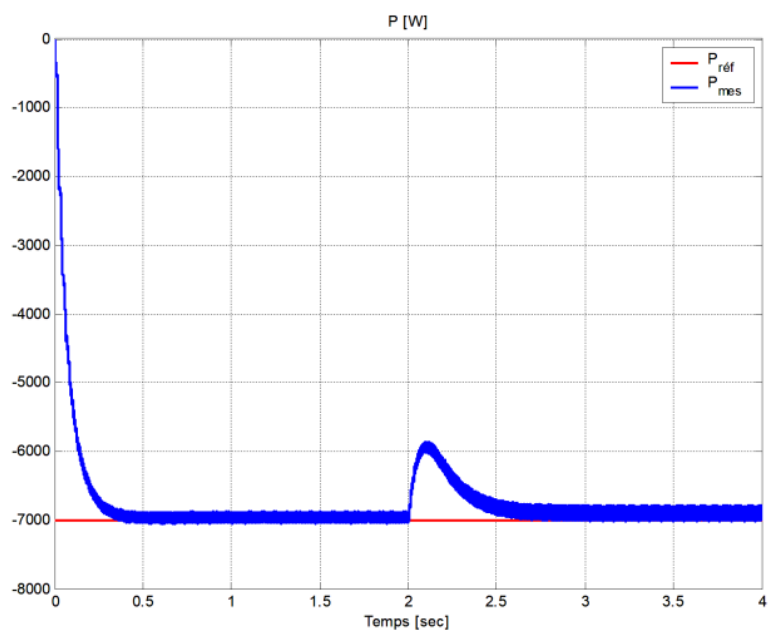

(a)

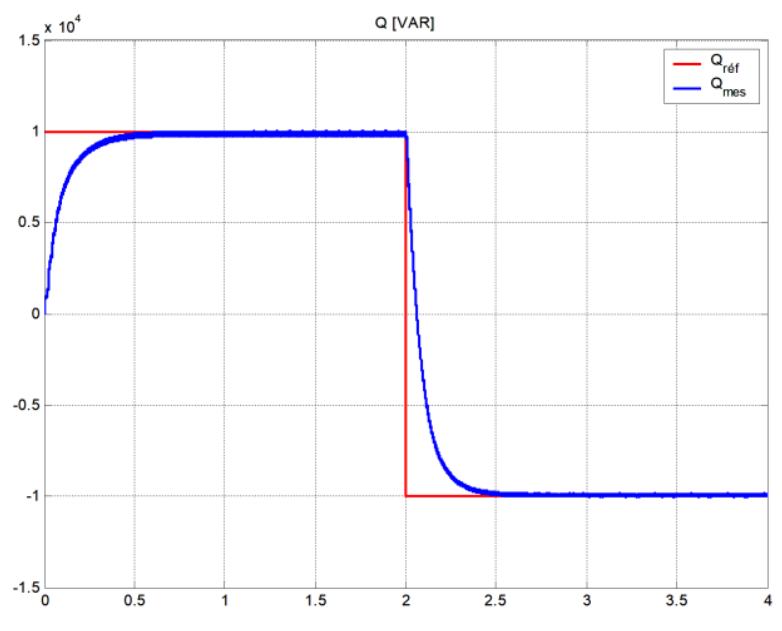

(b)

Figure 8. Simulation Results by fuzzy PI, $(\mathrm{P}=$ constant $)$, (a) responses of active power and (b) responses of reactive power 


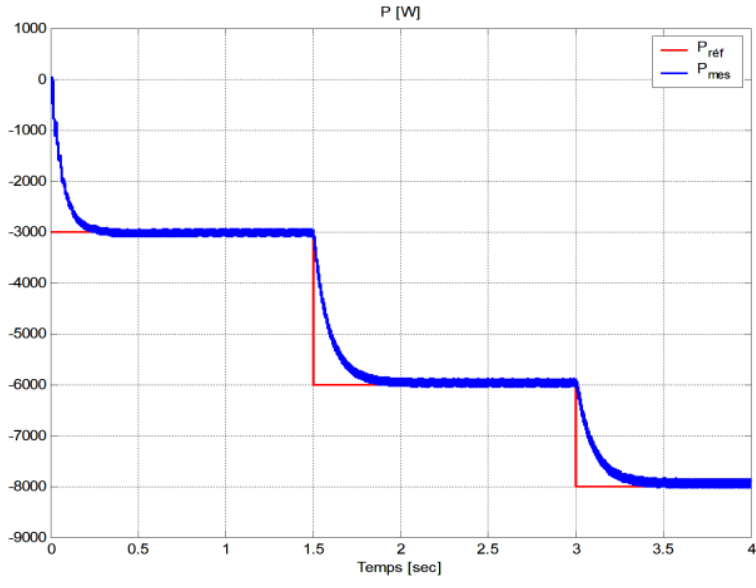

(a)

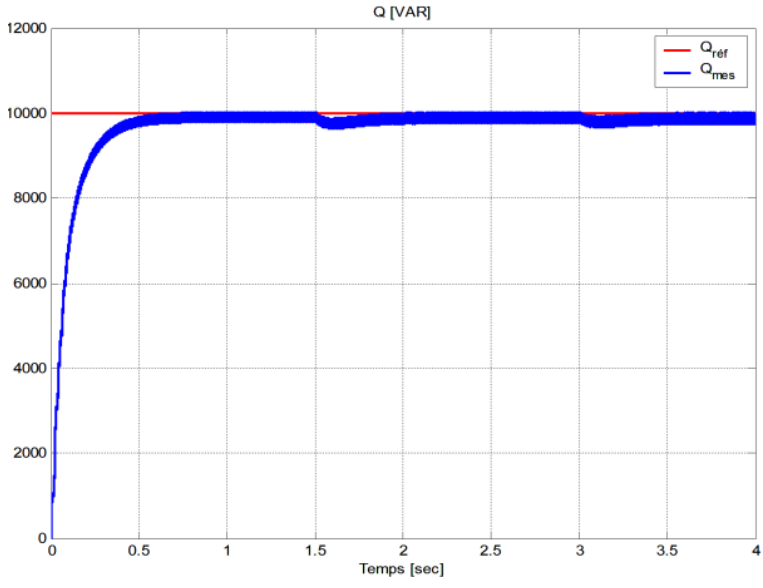

(b)

Figure 9. Simulation Results by fuzzy PI, (Q = constant), (a) responses of active power and

(b) responses of reactive power

\subsection{Adaptive fuzzy controller}

In order to improve the response of the system a more robust adaptive fuzzy controller is proposed. The performances of this controller are illustrated in the following simulation results. Figures 10 and 11 show the dynamic response for the different step values on the active and reactive power whereas Figures 12 and 13 show the evolution of the gains when the set points change.

Results of the adaptive fuzzy show clearly improved dynamic response of active and reactive power without overshoot for reactive power. Both powers reach their references in $0.15 \mathrm{sec}$. It is the best response time, compared with that obtained by the classic fuzzy controller. When change orders, we see that the adaptive gains changes values and they regain their previous values along the steady state. It follows that adaptation gains ensures system stability.

This Figures confirms convergence of the measured variables to reference variables. The results show the superiority of adaptive fuzzy controller with a better response time. So, the decoupling is unaffected It still persists. That shows the robustness of controller. In Figure 13. We can see that gains adapt to every change orders and ensures fast powers converges desired values.

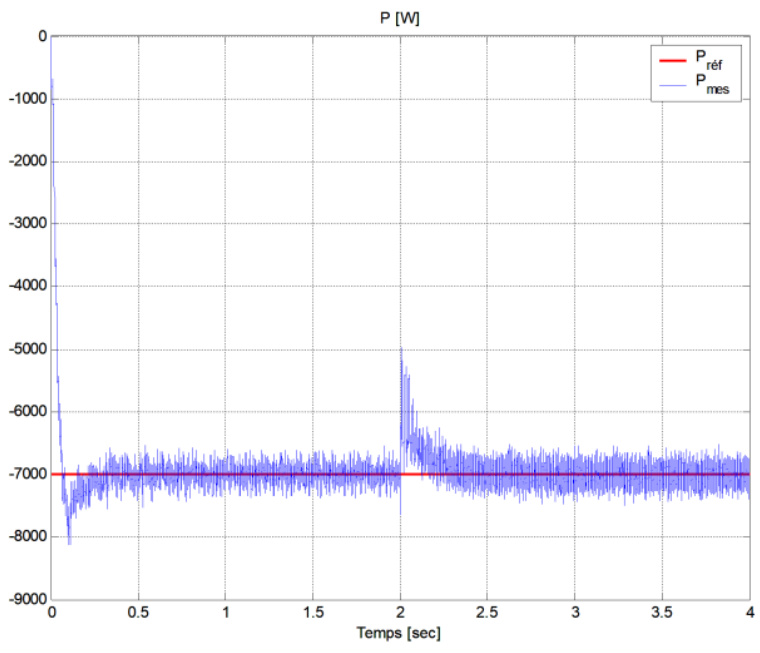

(a)

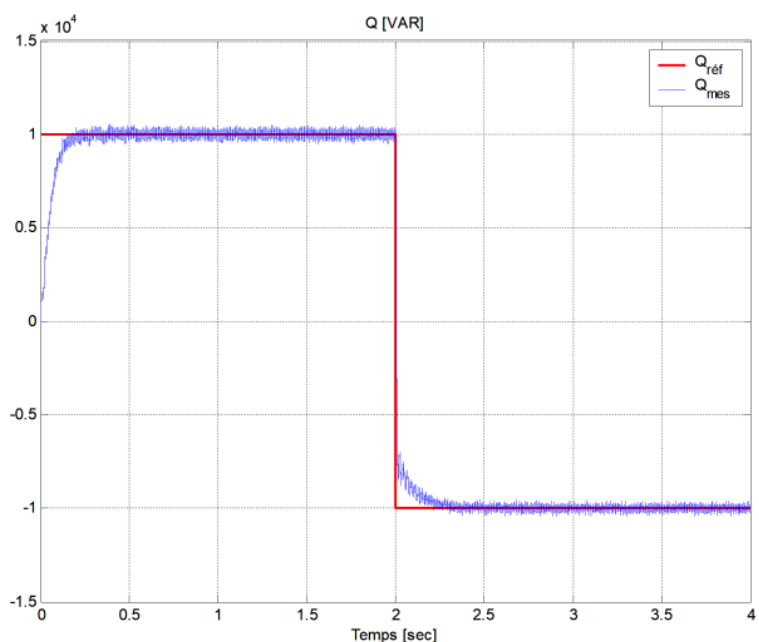

(b)

Figure 10. Simulation results of the adaptive fuzzy PID controller, (a) responses of active power and (b) responses of reactive power 


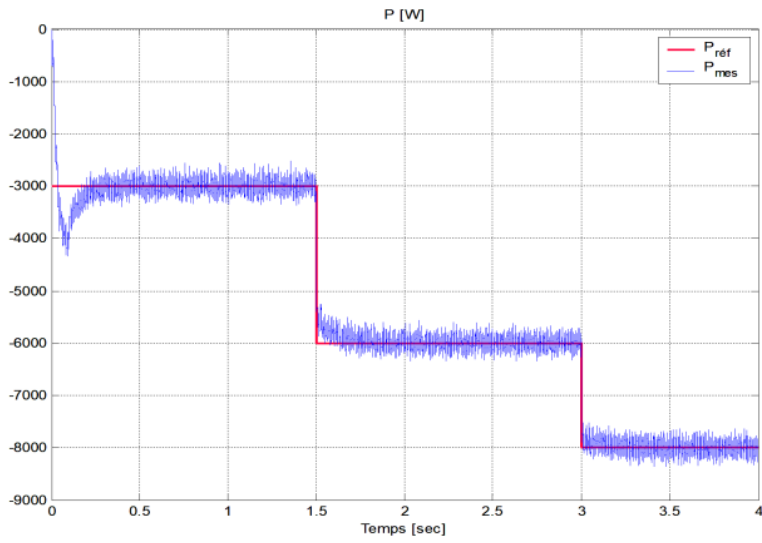

(a)

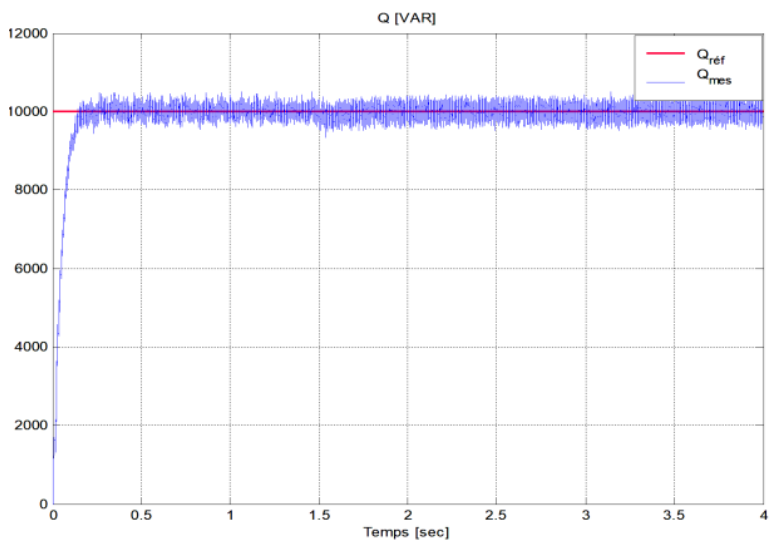

(b)

Figure 11. Simulation results of the adaptive fuzzy PID controller, (a) responses of active power and (b) responses of reactive power

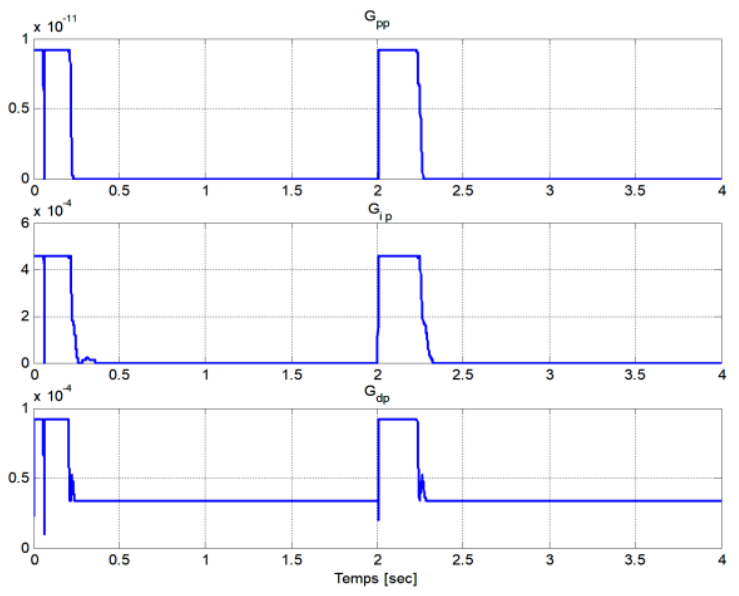

(a)
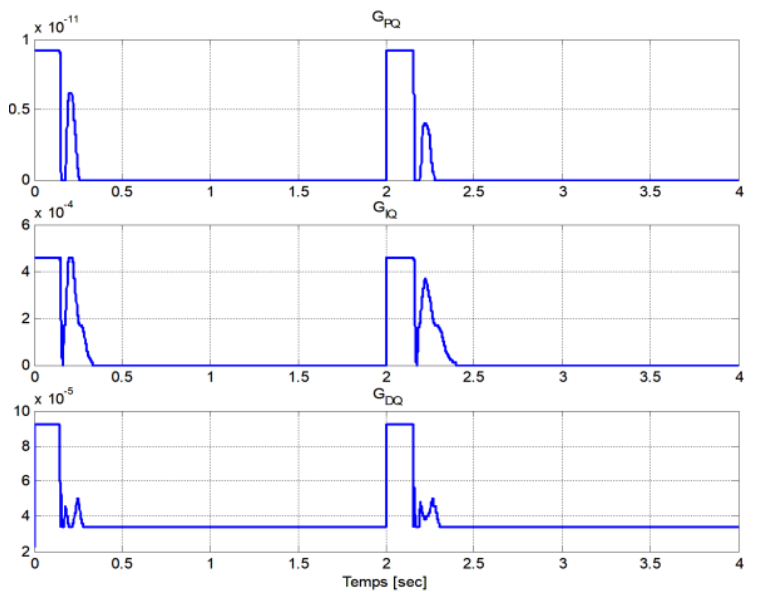

(b)

Figure 12. Adaptation gains for active (a) and reactive (b) power

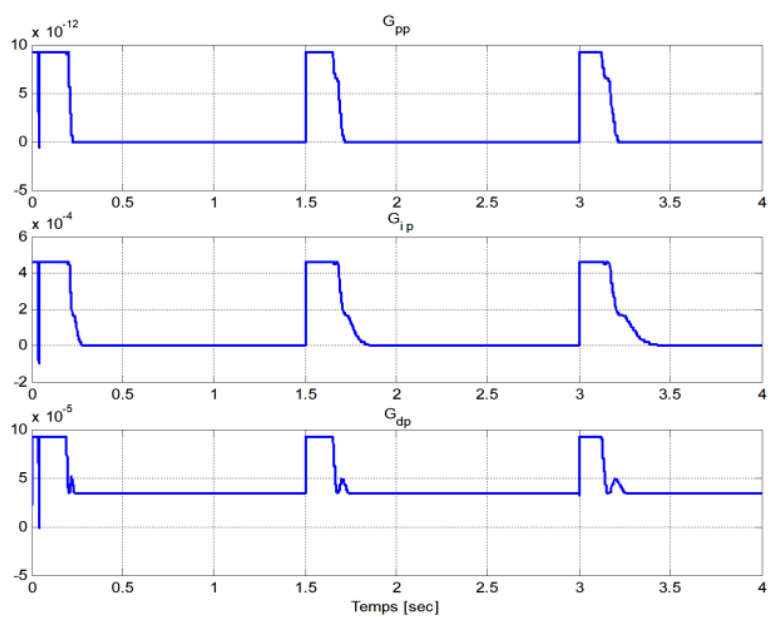

(a)
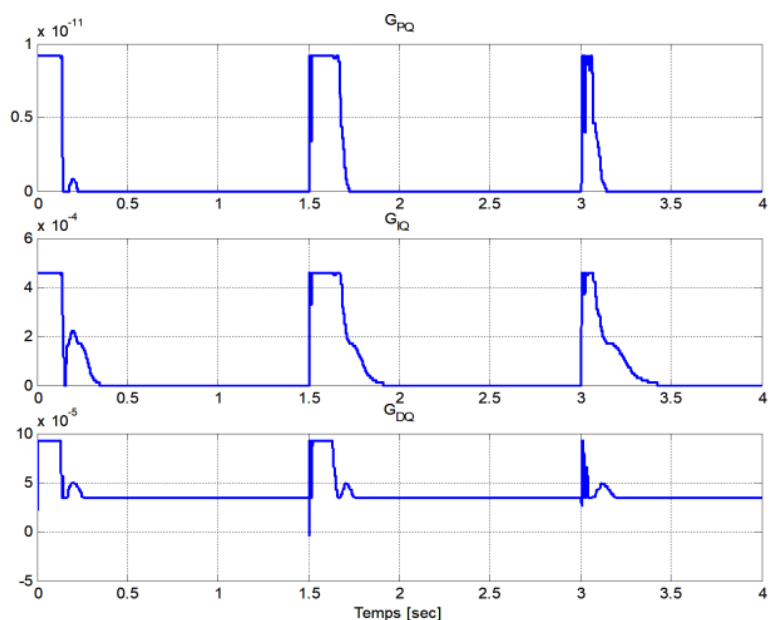

(b)

Figure 13. Adaptation gains for active, (a) and reactive (b) power 


\subsection{Discussion and comparative study}

\subsubsection{PI fuzzy controller}

The results obtained show that the references of active and reactive power imposed on the DFIG are followed without overshoot and with a much improved response time of $0.225 \mathrm{sec}$ for the active power and $0.35 \mathrm{sec}$ for the reactive power. Also the coupling between the two powers has been reduced.

\subsubsection{Adaptive PID fuzzy controller}

The simulation results of Figures 10 and 12 show clearly improved dynamic response of active and reactive power with no overshoot on the response of the reactive power. The two powers reach their references in a $0.15 \mathrm{sec}$ response time, therefore a faster and better response as compared to that of the fuzzy PI. In addition, the decoupling is maintained which demonstrates the robustness of this controller. It can be noticed from Figures 11 and 13 that during the set point change, the adaptive gains, assume large transient values and then return back to their previous values throughout the steady state which ensures system stability. Figures 14(a) and (b); show the comparison of the behavior of the both controllers in terms of tracking of the references. Through the comparative study, it can be seen that the tow regulators for step changes of active and reactive powers, give almost the same profile in terms of tracking for the different tests applied to the doubly fed induction generator, but with better transient response time with adaptive fuzzy controller.

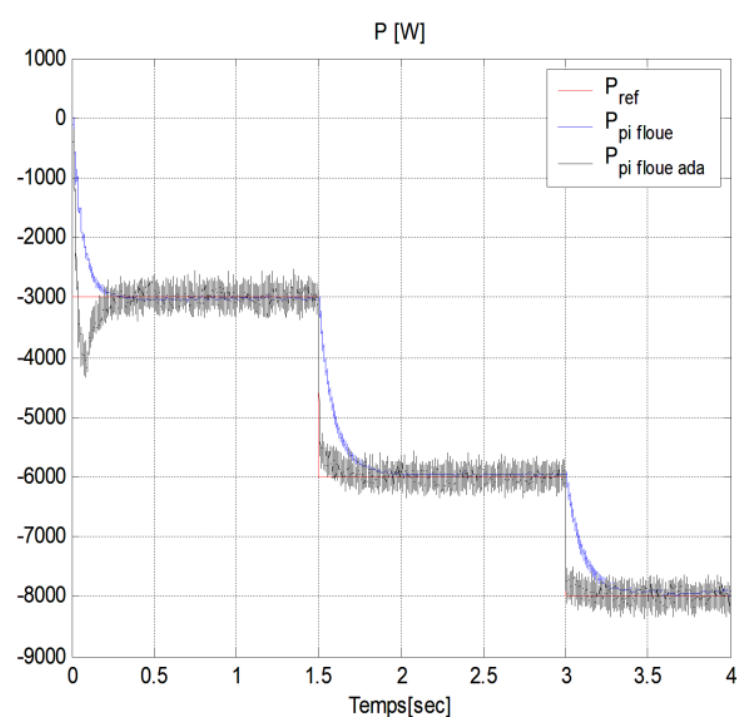

(a)

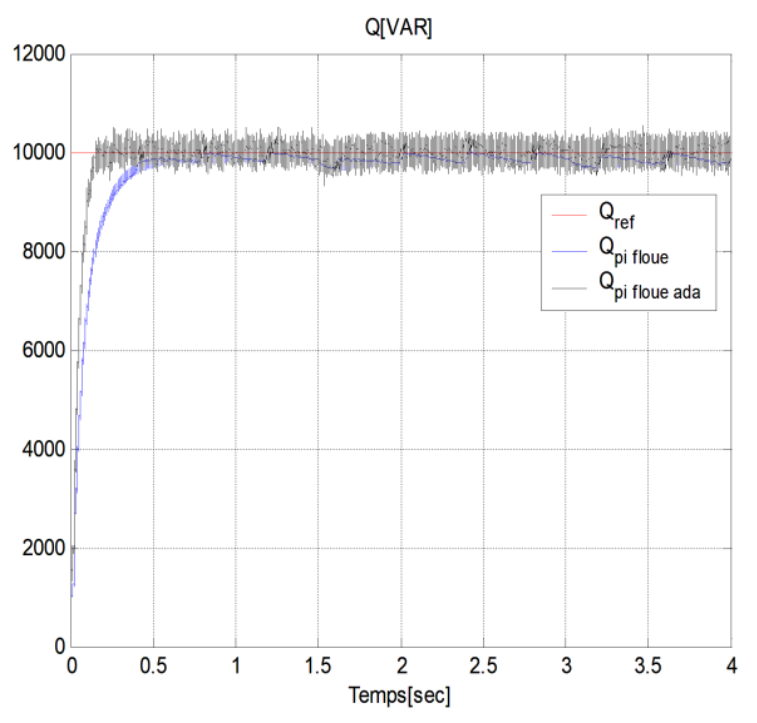

(b)

Figure 14. Comparison between PI Fuzzy control and PID adaptive fuzzy control, (a) responses of active power and (b) responses of reactive power

\subsection{Robustness test}

This test is performed to evaluate the robustness of the controller with respect to changes in the stator resistance. The stator resistance is changed by $80 \%$ of its nominal value. $\left(R_{S}=R_{S}+0.8 \times R_{S}\right)$ Indeed, controllers design are based on transfer functions whose settings are assumed to be fixed. However, in a real system, these parameters are subject to variations caused by different physical phenomena (heating resistors, inductors saturation).

Test conditions: Active power remains constant at $-6000 \mathrm{~W}$.

- The reactive power of the machine is also maintained constant and equal to $10000 \mathrm{VAR}$.

- At $\mathrm{t}=1.5 \mathrm{sec}$, the value of the stator resistance was increased by $80 \%$ of its nominal value.

Figure 15 shows the simulation results based on a fuzzy controller against changes Stator resistance. However, we can see influenced by this change by an apparition of fluctuations powers that take a time to stabilize. From Figures 16 and 17 we clearly note that this parametric change is not affected control powers and no side effect, which proves that adaptive fuzzy controller has high robust against the variation, moreover it appear that gains adapt at a variation of resistance and ensure the stability of powers. 


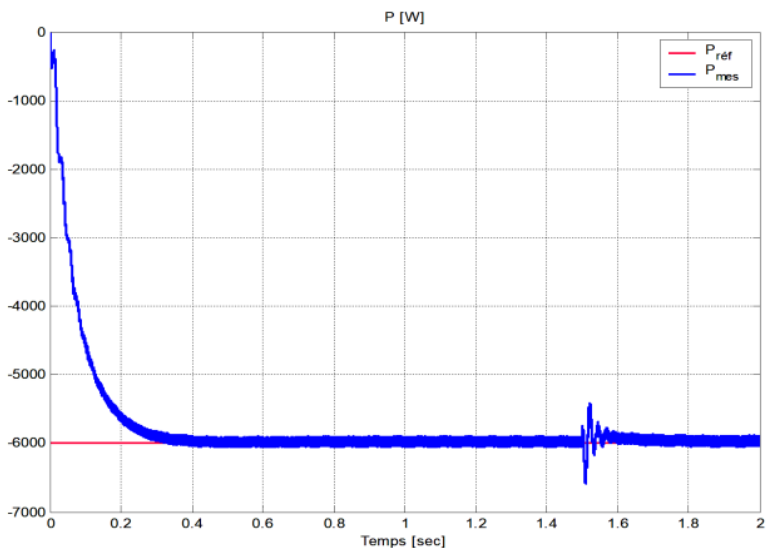

(a)

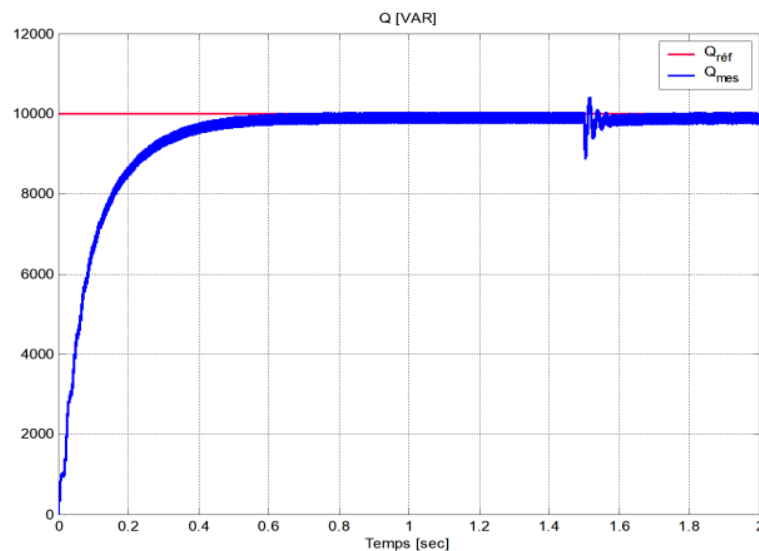

(b)

Figure 15. Simulation results per PI fuzzy for a $80 \%$ increase of $R_{s}$, (a) responses of active power and (b) responses of reactive power

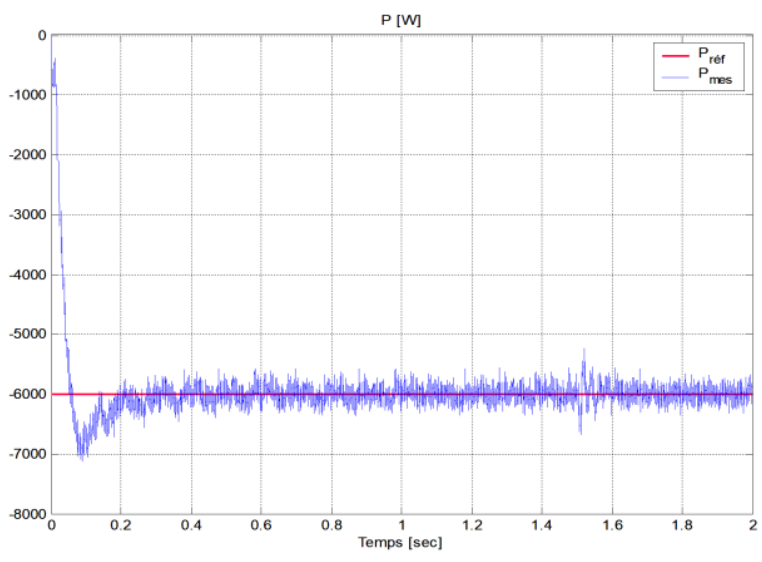

(a)

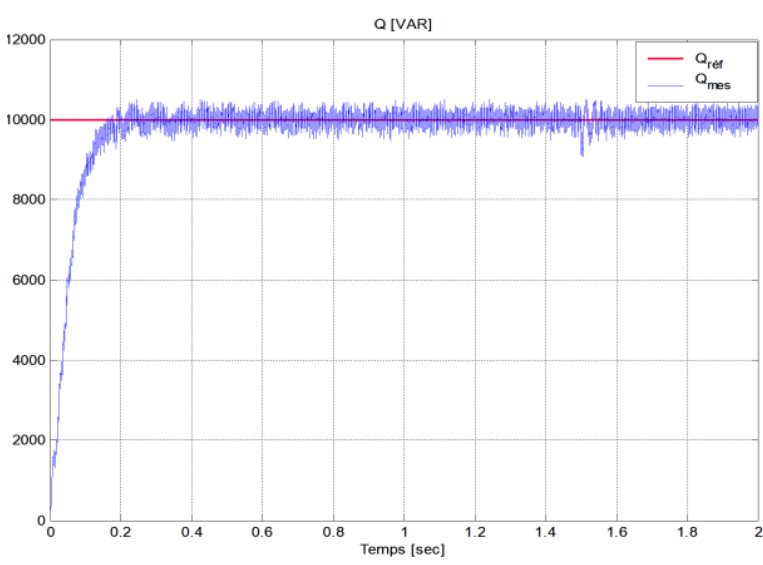

(b)

Figure 16. Simulation results per PID adaptive fuzzy for a $80 \%$ increase of $R_{S}$, (a) responses of active power and (b) responses of reactive power
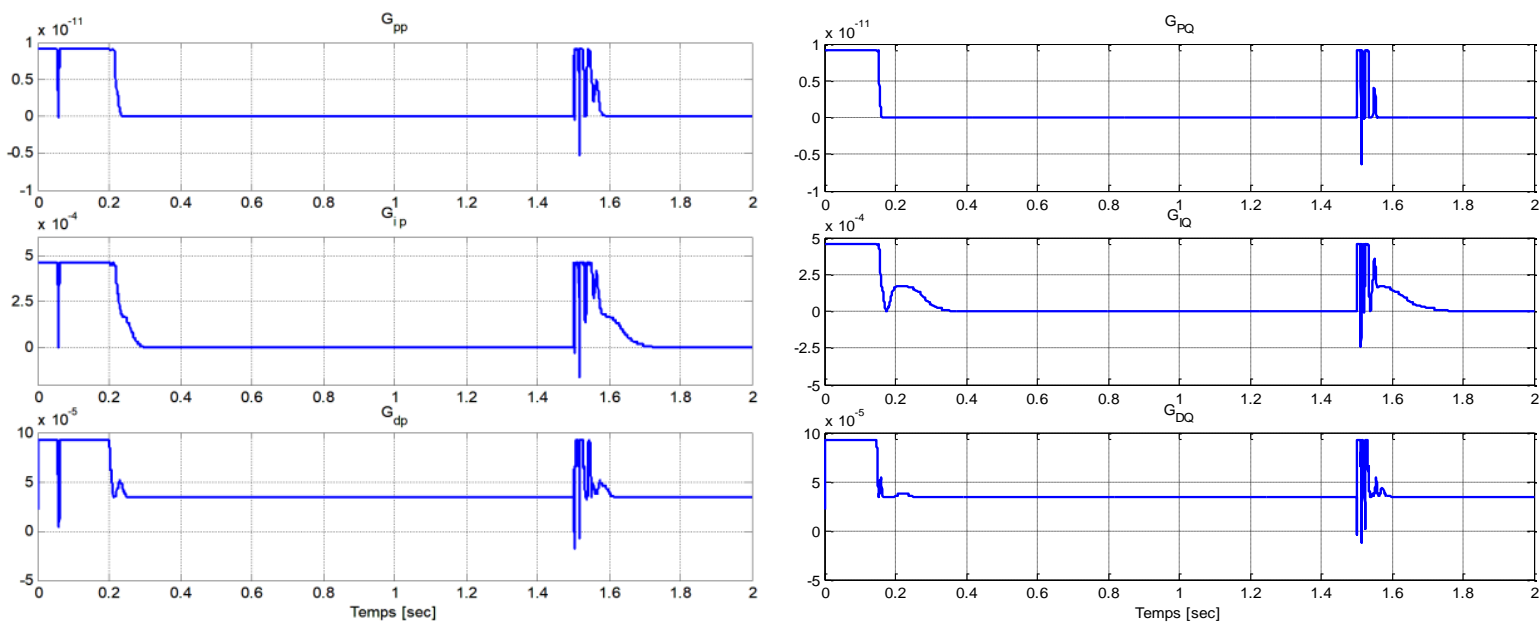

(a)

(b)

Figure 17. Adaptation gains for active (a) and reactive (b) power 


\subsubsection{Discussion and comparative study}

The objective of robustness test is to compare the performance of the controllers when machine's parameters change. In order to test the robustness of each controller, at $t=1.5 \mathrm{sec}$ we apply a sudden $80 \%$ increase inthe stator resistance. Consequently, this change will lead to a disruption of power. From these simulation results, it is noted that primarily the variation in the stator resistance do not deteriorate the performance ofthe proposed controller and have minimal impact on the system. Figure 15 shows the simulation results based on a fuzzy controller against the variation in the stator resistance, we note that, at the time of the increase of the resistance, small oscillations appear in the response of the powers. From Figure 16 we clearly notice that this parametric variation did not affect the response of the powers and causes no adverse reaction, which demonstrates that the adaptive fuzzy controller has strong robustness against this variation. In addition, it appears from Figure 17 that the adaptation gains are re-adjusted following the variation of the resistance and ensure the stability of power. Thus, we can conclude from these results that the adaptive fuzzy controller is more powerful than the conventional one. The following Table 4 summarize and compare the performance of controllers.

Table 4. Comparative of the performance of controllers

\begin{tabular}{lcccc}
\hline & \multicolumn{2}{c}{ reactive power P } & \multicolumn{2}{c}{ active power Q } \\
& fuzzy & Adaptive fuzzy & fuzzy & Adaptive fuzzy \\
\hline Settling Time 5\% & 0.35 & 0.15 & 0.225 & 0.15 \\
Steady State Error \% & 0.4 & 0 & 0.4 & 0 \\
Overshoot \% & 0 & 0 & 0 & 14.3 \\
Stabilization Time (Sec) & 0.6 & 0.17 & 0.35 & 0.21 \\
Rise Time 63\% (Sec) & 0.087 & 0.052 & 0.064 & 0.021 \\
\hline
\end{tabular}

\section{CONCLUSION}

This paper is devoted to the electrical energy production on the grid by using the doubly fed induction generator (DFIG) based Wind Energy Conversion System. The conception of the machine permits to control the power exchanged between the stator and the grid by modifying rotor voltage via a bidirectional converter. To achieve this, a vector control of the generator is done with active and reactive stator powers as control variables using two control approaches, fuzzy and adaptive fuzzy controller. Actually the difference both regulators is insignificant in terms of tracking of the references, However in terms of dynamic response, the settling time, peak overshoot of values, oscillation damping and robustness we saw the superiority in adaptive fuzzy controller with results that are more efficient and very successful, moreover, with adaptive fuzzy controller we'll have : 1) A reduced response time; 2) A small overshoot and oscillation are amortized quickly; 3) The transitional regime is better than the other one. 4) A good robustness.

The presented study makes a path for research and obtains optimal solution of the studied system. We hope and plan as perspective: (1) Developed other nonlinear control laws to other more powerful controllers. (2) Study a system including a wind farm depth study of disturbances inherent coupling device with the network. (3) Set up experimental Test Stand validate the performance of controllers used in this article.

\section{REFERENCES}

[1] The wind newspaper series N 12, "Wind Barometer Eurobserver," EurObservER, 2013. [Online], Available: www.eurobserv-er.org/pdf/EurObservER-Press-Reviews-2013.pdf,

[2] Boyette A, "Control and Command of an Asynchronous Generator with a System of Storage for the Wind production," Ph.D. Thesis Electrical energy, University Henri Poincare, 2006.

[3] Fichaux N., and Wilkes J, "Oceans of opportunity-harnessing Europe's largest domestic energy resource- Editor," European Wind Energy Association EWEA, 2009.

[4] Poitiers F, "Study and control of induction generators for wind energy conversion systems," Ph.D Thesis, Electrical energy, University of Nantes, 2003.

[5] Osmic, J., Kusljugic, M., Becirovic, E., and Toal, D., "Analysis of active power control algorithms of variable speed wind generators for power system frequency stabilization," Turk J Elec Eng \& Comp Sci, vol. 24, no. 1, pp. 234-246, 2016.

[6] Siegfriedd H., "Grid Integration of Wind Energy Conversion Systems," John Wiley \& Sons Ltd, 1998.

[7] Md. Rabiul Islam, Youguang G., and Jian G. Z., "Steady State Characteristic Simulation of DFIG for Wind Power System," IEEE Trans. Electrical and Computer Engineering, pp. 151-154, 2010.

[8] Saget C, "The electronic variation of speed in the service of the electric power production by wind turbine," Review of the electricity and the electronics, 1998.

[9] Abdin E. S, and Xu W, "Control design and Dynamic Performance Analysis of a Wind Turbine-Induction Generator Unit," IEEE Transactions on Energy Conversion, vol. 15, no. 1, pp. 91-96, 2000. 
[10] Belmokhtar, K., Doumbia, M. L., and Agbossou, K, "Modelling and fuzzy logic control of DFIG based Wind Energy Conversion Systems," IEEE International Symposium on Industrial Electronics, pp. 1888-1993, 2012

[11] Altun, H., and Sünter, S., "Modeling, Simulation and Control of Wind Turbine Driven Doubly-Fed Induction Generator with Matrix Converter on the Rotor Side," Electrical Engineering, vol. 95, no. 2, pp. 157-170, 2013.

[12] Suman. M., Debaprasad, K., "Improved Direct Torque and Reactive Power Controlof a Matrix Converter Fed Grid Connected DoublyFed Induction Generator," IEEE Transactions on Industrial Electronics, vol, 62, no. 12, pp. 7590-7598, 2015.

[13] Guo, W., Liu, F., He, D., Si, J., Harley, R., and Mei, S., "Reactive power control of DFIG wind farm using online supplementary learning controller based on approximate dynamic programming," IEEE International Joint Conference Neural Networks, pp. 1453-1460, 2014.

[14] Hocini Y., "control of generator for wind energy conversion systems," Magister Thesis, University of the sciences and the technology of Oran, 2013.

[15] Ardjoun S. A. E, and Abid M, "Fuzzy sliding mode control applied to a doubly fed induction generator for wind turbines," Turk J Elec Eng \& Comp Sci, vol. 23, no. 6, pp. 1673-1686, 2015.

[16] Jian Y, Dongran S. and al, "The integrated control of fuzzy logic and model-based approach for variable-speed wind turbine," Turk J Elec Eng \& Comp Sci, vol. 23, no. 6, pp. 1715-1734, 2015.

[17] Sun L, and Chen Y, et al., "Control winding current-oriented control for stand-alone brushless doubly fed power generation system," IEEE Energy Conversion Congress and Exposition, pp. 2776-2781, 2015.

[18] Siraj K, Siraj H, and Nasir M, "Modeling and control of a doubly fed induction generator for grid integrated wind turbine," 16th International Power Electronics and Motion Control Conference and Exposition, pp. 901-906, 2014.

[19] Saghafinia Z. A, Wooi Ping H. High, "Performance Induction Motor Drive Using Fuzzy Self-Tuning Hybrid Fuzzy Controller," IEEE International Conference on Power and Energy, pp. 468-473, 2010.

[20] Kouzi K, Mokrani L, and al, "New Design of Fuzzy Logic Controller with Fuzzy Adapted Gains Based on Indirect Vector Control for Induction Motor Drive," Proceedings of the 35th South-eastern Symposium on System Theory, pp. 362-366, 2003.

[21] Krzysztof W, "Output Feedback Direct Adaptive Fuzzy Controller Based on Frequency-Domain Methods," IEEE Transactions on Fuzzy Systems, vol. 24, no. 3, pp. 622-634, 2016.

[22] Gilbert C., Sousa D., and Bose B. K., "Fuzzy logic applications to power electronics and drives - an overview," Proceedings of IECON'95-21 st Annual Conference on IEEE Industrial Electronics., vol. 1, pp. 57-62, 1995.

[23] Hsu Y. C. chen G. Li H. X, "A Fuzzy Adaptive Variable Structure Controller with Applications to Robot Manipulators," IEEE Trans. Syst., Man. \& Cybern, vol. 31, no. 3, pp. 331-340, 2001.

[24] Shi Y. Sen P. C.,"A New Defuzzi_cation Method for Fuzzy Control of Power Converters," Conf. Rec. IEEE-IAS, Annu. Meeting, 2000.

[25] Romeral L., laquet J., aldabas E., and Arias A, "A Simple Fuzzy Adaptive Speed Controller," Conf. Rec. IEEE-IAS, Аnпu. Meeting, 2000. 